\title{
GESTIÓN DE LOS BIENES EN LA COMUNIDAD DE GANANCIAS. PARALELISMOS ENTRE EL DERECHO ARGENTINO Y PERUANO ${ }^{1}$
}

\author{
Property management in the profit community. \\ Parallelisms between Argentine and Peruvian Law
}

Romina Santillán Santa Cruz ${ }^{2}$

DOI: $10.46553 /$ prudentia.89.2020.p87-114

Recibido: 2 de abril de 2020

Aprobado: 14 de abril de 2020

Resumen: Este trabajo ofrece un estudio de la gestión de los bienes en la comunidad de ganancias del Derecho argentino y sus paralelismos con el Derecho peruano. Este estudio resulta de interés porque, en 2015, Argentina incorporó en su legislación un sistema de elección y sustitución del régimen patrimonial del matrimonio, que está vigente en Perú desde 1984. A causa de esta nueva regulación, el Derecho argentino modifica las reglas a aplicarse en la calificación y gestión de los bienes conyugales. En la comunidad de ganancias rige el principio de gestión separada, con excepciones muy concretas. Muchas de estas reglas del Derecho argentino son novedosas en relación con las previstas en la sociedad de gananciales del Derecho peruano, que aún presenta problemas con la disposición individual de los bienes comunes. Bajo la óptica del derecho comparado, se analizan dichas reglas para valorar la posibilidad de su adopción en la legislación peruana.

1 Este trabajo ha sido realizado en el marco del Grupo Consolidado de Investigación del Gobierno de Aragón Ius Familiae, IP. Carlos Martínez de Aguirre Aldaz. Es el resultado de una breve estancia de investigación desarrollada, en julio de 2016, en la Facultad de Derecho de la Pontificia Universidad Católica Argentina, bajo la tutoría de la profesora Úrsula C. Basset.

2 Investigadora contratada en la Facultad de Derecho de la Universidad de Zaragoza (España). Doctora en Derecho y Máster en Especialización e Investigación en Derecho, con mención en Derecho de la Familia y de la Persona, por la Universidad de Zaragoza (España). Abogada por la Universidad Católica Santo Toribio de Mogrovejo (Perú). Correo electrónico: rsantillan@unizar.es 
Palabras clave: Comunidad de bienes; Actos de administración; Actos de disposición; Derecho argentino; Derecho peruano.

Abstract: This work offers a study of management of property in the community of property of Argentine Law and its similarities with Peruvian Law. This study is interesting since, in 2015, Argentina incorporated in its legislation a system of choice and substitution of the patrimonial regime of marriage, which has already been in force in Peru since 1984. Because of this new regulation, Argentine Law changes the rules to be applied in the qualification and management of marital property. In the community of property, the principle of separate management applies, with very specific exceptions. Many of these rules of Argentine Law are novel in relation to those provided in the community of property of Peruvian Law, which still presents problems with the individual disposition of common property. For this reason, the analysis is made from a comparative law perspective to assess the possibility of adopting such rules in Peruvian legislation.

Keywords: Community of property; Acts of administration; Acts of disposition; Argentine Law; Peruvian Law.

Sommario: Questo lavoro offre uno studio sulla gestione dei beni nella comunione dei beni del diritto argentino e le sue somiglianze con il diritto peruviano. Questo studio è interessante perché, nel 2015, l'Argentina ha recepito nella sua legislazione un sistema di scelta e di sostituzione del regime patrimoniale del matrimonio, in vigore in Perù dal 1984. A causa di questa nuova regolamentazione, il diritto argentino modifica le regole da applicare nella qualificazione e gestione dei beni coniugali. Nella comunione dei beni vige il principio della gestione separata, con eccezioni molto specifiche. Molte di queste norme del diritto argentino sono nuove rispetto a quelle previste nella comunione dei beni del diritto peruviano, che presenta ancora problemi con la disposizione individuale dei beni comuni. L'analisi è effettuata nell'ottica del diritto comparato per valutare la possibilità di adottare tali norme nella legislazione peruviana.

Parole chiave: Comunione dei beni; Atti di amministrazione; Atti di disposizione; Diritto argentino; Diritto peruviano.

Para citar este artículo:

Santillán Santa Cruz, R. (2020). "Gestión de los bienes en la comunidad de ganancias. Paralelismos entre el Derecho argentino y peruano".

Prudentia Iuris, N. 89, pp. 87-114. 


\section{Estado de la cuestión}

Este trabajo aborda el estudio de la gestión de los bienes en el régimen matrimonial de comunidad de ganancias regulado por el nuevo Código Civil y Comercial de la Nación (en adelante, CCCN), vigente en Argentina desde el 1 de agosto de 2015. El sistema económico matrimonial que implanta este nuevo Código responde firmemente a esa tendencia evolutiva propia de las legislaciones modernas que claman una adecuación real y efectiva de sus normas al escenario social que pretenden regular. Se buscaba, de este modo, adaptar el marco legal regulatorio del régimen de bienes a la nueva realidad producida como consecuencia de los constantes cambios sociales que iban introduciéndose en los ámbitos laboral-económico y jurídico de las familias en el país.

Esta nueva normativa desplaza al Código de Vélez Sarsfield, cuya vigencia dató desde 1971 hasta el 31 de julio de 2015. Este Código se había caracterizado por la imposición de un régimen imperativo ex lege, único y forzoso, al que los cónyuges debían sujetarse sin opción alguna ${ }^{3}$. Una imperatividad que se mantuvo así, tanto pese a los cuestionamientos doctrinales ${ }^{4}$, que consideraban oportuno dar un ámbito de mayor autonomía de voluntad a los cónyuges en asuntos patrimoniales, como a las continuas reformas legislativas introducidas al citado Código ${ }^{5}$. La inserción de la mujer en el ámbito laboral, la necesidad de introducir nuevas formas de tutela al interés familiar y el exigido respeto a la igualdad jurídica entre cónyuges ${ }^{6}$, motivaron la sanción de un nuevo Código, cuya principal novedad es, sin lugar a dudas, la posibilidad de elegir el régimen patrimonial del matrimonio antes de su celebración, aunque restringida a dos regímenes concretos, y de pactar su modificación durante la vigencia del mismo.

3 Conf. Basset, U. C. (2010). La calificación de bienes en la sociedad conyugal: principios, reglas, criterios y supuestos. Buenos Aires. AbeledoPerrot, 64; y, Cagnasso, A. (2016). "El régimen patrimonial del matrimonio en el nuevo Código Civil y Comercial de la Nación”. En El Derecho, $\mathrm{N}^{\circ} 71 /-8,1$.

4 Conf. Sambrizzi, E. A. (2015). El régimen patrimonial del matrimonio en el nuevo Código Civil y Comercial. Ciudad Autónoma de Buenos Aires. Thomson Reuters La Ley, 6-7; Basset, U. C. et al. (2015). "Tomo III. Artículos 401 a 723. Relaciones de Familia". En Alterini, J. H. (Dir. Gen.). Código Civil y Comercial comentado. Tratado Exegético. Ciudad Autónoma de Buenos Aires. La Ley, 187; y, Medina, G. (2012). "El régimen patrimonial del matrimonio en la reforma al Código Civil y Comercial”. En Revista de Derecho de Familia y Persona, No 3, 1. [Cita Online: AR/DOC/5230/2012].

5 Las reformas parciales introducidas al Código de Vélez Sarsfield, pueden verse en Basset, U. C. et al. (2015). "Tomo III. Artículos 401 a..." Ob. cit., 187-189.

6 Conf. Ibídem, 186. 
Se permite a los cónyuges optar, mediante convención matrimonial, por una separación de bienes o una comunidad de ganancias, aplicándose supletoriamente esta última ante la ausencia de elección expresa. Los cónyuges pueden modificar el régimen cuantas veces quieran sin más limitación que el plazo legal exigido para su procedencia ${ }^{7}$-el art. 449 CCCN requiere que haya transcurrido un año desde la aplicación del régimen o desde la última modificación-. Existen, además, una serie de disposiciones comunes a todos los regímenes, que son inderogables, salvo preceptos en contrario. Siendo de especial interés para esta investigación el estudio del régimen de comunidad de ganancias.

El CCCN regula un sistema de titularidad diferenciada de los bienes habidos durante la vigencia de la comunidad de ganancias. En esta comunidad coexisten varias masas de bienes: las conformadas, respectivamente, por los bienes propios y gananciales de titularidad de cada cónyuge, y aquellas, a su vez, compuestas por los bienes propios y gananciales conjuntamente adquiridos. Unos y otros bienes se distinguen por el momento de su adquisición, así como por el modo en que se realizará su gestión, de acuerdo con las previsiones que aparecen en el Código, basadas principalmente en la protección de los cónyuges, el interés familiar y la seguridad jurídica de los terceros.

Tal diferenciación se advierte, con mayores matices, en las reglas de gestión, pues en estas se pone de relieve el nivel de participación que tendrá cada cónyuge en los actos de disposición y administración según cual fuere la naturaleza de los bienes. La gestión de los bienes constante comunidad de ganancias descansa, en general, sobre el principio de gestión separada. Sin embargo, en forma excepcional, para determinados casos, se requiere el asentimiento del otro cónyuge, es decir, de aquel que no es titular de los bienes propios y gananciales a gestionarse. He de resaltar que existe una regulación clara y precisa sobre el tipo de actuación requerida al cónyuge no titular, y también de los bienes en relación con los cuales aquella actuación será requerida.

Vistas estas cuestiones, se plantea reseñar algunos paralelismos entre el Derecho argentino y peruano. Si bien, a diferencia del primero, en este último no se ha regulado un mecanismo de convenciones matrimoniales ${ }^{8}$, ambos sí comparten el modelo de libre elección y sustitución del régimen económico -vigente en Perú desde 1984-. En Derecho peruano, los regíme-

7 Conf. Roveda, E. G. (2015). “Convenciones matrimoniales”. En Rivera, J. C. \& Medina, G. (Dirs.). Código Civil y Comercial de la Nación comentado. Tomo II. Ciudad Autónoma de Buenos Aires. La Ley, 100.

8 Conf. Aguilar Llanos, B. (2008). La Familia en el Código Civil peruano. Lima. Ediciones Legales, 136. 
nes matrimoniales y sus correspondientes efectos ya vienen determinados por el Código Civil (en adelante, CC), dejándose a discrecionalidad de los cónyuges únicamente la elección del mismo $^{9}$, o su modificación ${ }^{10}$, bajo una formalidad solemne cuya inobservancia es sancionada con nulidad absoluta. Estos regímenes son el de sociedad de gananciales y el de separación de patrimonios, debiendo sujetarse la voluntad de los contrayentes o casados a lo establecido en las normas para cada caso. El régimen de gananciales opera con carácter supletorio.

En la sociedad de gananciales -como se denomina a la comunidad de bienes en el Derecho peruano- puede haber bienes propios de cada cónyuge y bienes sociales, que no son otros que aquellos a los que el Derecho argentino denomina gananciales -este último concepto es reservado por el CC para otro tipo de bienes: los remanentes tras el proceso de liquidación del régimen-. No existe en Perú -a diferencia de lo que sucede en la legislación civil y comercial de Argentina- una tipología de los bienes comunes en función del cónyuge que los adquirió, que permita hablar de bienes comunes de cada cónyuge o adquiridos conjuntamente, como para trazar a partir de allí unas reglas sobre la gestión de los bienes basadas en esta diferenciación legal.

Existe una sola clase de bienes comunes: los adquiridos onerosamente durante la vigencia de la sociedad de gananciales -y los que no puedan ser calificados como propios de cada cónyuge, al operar aquí la presunción de ganancialidad-. Se exige una coparticipación en la disposición y gravamen de dichos bienes, incluso mediante poder especial otorgado por un cónyuge al otro para la realización de dichos actos, salvo que se trate de supuestos previstos en las leyes especiales o de la adquisición de bienes muebles, como luego se analiza. La representación especial prescrita para la disposición de los bienes sociales presenta problemas en la práctica jurídica.

Se cuestiona la disposición individual de bienes sociales en supuestos para los que la ley exige dicho poder especial. Se plantea un problema de contravención de la regla de codisposición, pero la norma no prevé sanción expresa ante la ausencia de dicho poder. La jurisprudencia no ha sido ca-

9 Conf. Plácido Vilcachagua, A. (2007). "Elección y formalidades del régimen patrimonial”. En Gutiérrez Camacho, W. (Dir.). Código Civil comentado. Derecho de Familia (Primera parte). Tomo II. $2^{\text {a }}$ ed. Lima. Gaceta Jurídica, 179.

10 Conf. Plácido Vilcachagua, A. (2007). "Sustitución voluntaria del régimen patrimonial”. En Gutiérrez Camacho, W. (Dir.). Código Civil comentado. Derecho de Familia (Primera parte). Tomo II. $2^{\text {a }}$ ed. Lima. Gaceta Jurídica, 184. La sustitución convencional del régimen puede ser realizada cuantas veces los cónyuges lo estimen conveniente, pues la norma de la materia no fija límite alguno sobre este punto. El Derecho peruano difiere del argentino, por cuanto este establece un plazo legal para que los cónyuges puedan variar el régimen inicialmente elegido. 
paz de ofrecer soluciones unánimes frente a ese caso, fijando criterios poco constantes e inestables. Unas decisiones judiciales se muestran a favor de la nulidad, y otras, en favor de la ineficacia. La doctrina, por su parte, experimenta una inestabilidad similar a la de la jurisprudencia, con la agravante de que se recurre a más tipos de invalidez e ineficacia, diversificando de este modo el problema y sus posibles soluciones.

A diferencia del escenario que genera la ausencia de ciertas reglas en el Derecho peruano, en el nuevo Código Civil y Comercial argentino existen unas reglas más claras y una mayor libertad para la administración y disposición de los bienes dentro del régimen de comunidad de ganancias cualquiera que fuere la naturaleza de aquellos (propios o gananciales de cada cónyuge), cuyo contenido normativo y alcance, como se había anticipado, constituye justamente el objeto central de este estudio. Concretado que sea este objetivo, se pretende valorar, bajo la óptica del derecho comparado, la posibilidad de su adopción en la legislación peruana.

La finalidad de este estudio del Derecho argentino y peruano no es meramente comparativa. Tiene el objetivo de realizar un análisis de las reglas sobre gestión de los bienes bajo un régimen de comunidad en dos ordenamientos legales formulados en dos momentos diferentes, siendo el Derecho argentino el que en cierta medida suscita un especial atractivo por tratarse de un Derecho reciente que, en relación con otros países latinoamericanos, aporta una técnica novedosa en la forma de abordar el asunto. Ello tiene como consecuencia, en primer lugar, enriquecer el análisis con materiales procedentes de ambos Derechos. Al mismo tiempo, este estudio comparativo se dirige también a producir resultados beneficiosos para los dos ordenamientos implicados, y más en general para la determinación de mejoras técnicas en la regulación de la materia en cuestión.

Con dicho objeto, se presenta en este trabajo un breve estudio de la comunidad de ganancias para así comprender la gestión de los bienes en este régimen, analizando en especial el contenido y alcance de la exigencia legal del asentimiento conyugal en la administración y disposición de determinados bienes. Así mismo, se hace un análisis crítico del régimen de sociedad de gananciales regulado en el Derecho peruano y de la normativa aplicable a la gestión de los bienes, centrando un mayor estudio en los actos de disposición de los bienes comunes debido a los problemas que aquellos vienen generando. Para finalizar, me ocuparé de valorar sucintamente la posibilidad de adoptar las reglas de gestión de la comunidad de ganancias en el régimen peruano de gananciales. 


\section{Configuración legal del régimen de comunidad de ganancias}

En la regulación dada por el CCCN, la comunidad de ganancias es un régimen elegible ${ }^{11}$ que se caracteriza principalmente por la formación de una masa de bienes que, a su disolución, debe dividirse, por partes iguales, entre los esposos o entre estos y sus herederos ${ }^{12}$. Medina menciona que "durante la vigencia del matrimonio los cónyuges sólo tienen una expectativa sobre la mitad de los bienes y su derecho a la mitad de los gananciales recién surge al tiempo de la disolución"13. No obstante, existen discusiones doctrinales acerca del carácter actual o expectaticio del derecho del cónyuge sobre esa ganancialidad, que se predica respecto del total de los bienes gananciales, sea que fuesen de titularidad de un cónyuge o de ambos ${ }^{14}$.

La comunidad de ganancias rige con carácter supletorio. De principio, prima la libre voluntad de los cónyuges de elegir el régimen que gobernará sus relaciones patrimoniales procedentes del matrimonio, siendo que la comunidad de ganancias solo será aplicable supletoriamente a falta de esa expresa elección y, de ser el caso, únicamente hasta que los cónyuges decidan modificar el régimen respetando el plazo legal requerido para tal acto.

El régimen de comunidad de ganancias, sea que los futuros cónyuges lo hubiesen elegido vía convención matrimonial o se aplicara en forma supletoria debido a la ausencia de opción, rige desde el momento de la celebración del matrimonio. El art. $463 \mathrm{CCCN}$ preceptúa que no puede estipularse que el régimen de comunidad comience antes o después de la celebración del acto matrimonial -aunque en realidad, a tal efecto, esta disposición rige por igual en ambos regímenes (la vigencia del de separación de bienes también está supeditada a la celebración del matrimonio)-. El único y excepcional supuesto en que la comunidad puede operar después es el referido a la modificación del régimen, regulado por el art. 449 CCCN.

En cuanto a los bienes que pueden coexistir como parte del acervo patrimonial de los cónyuges durante la vigencia de un régimen de comunidad de ganancias, de acuerdo con la propia estructura del Código, se tienen seis tipos: los bienes propios y los gananciales de titularidad de cada cónyuge, así como los bienes propios y los gananciales conjuntamente adquiridos

11 Conf. Basset, U. C. et al. (2015). “Tomo III. Artículos 401 a...” Ob. cit., 192.

12 Conf. Medina, G. (2015). "Disposiciones generales del Régimen de comunidad”. En Rivera, J. C. \& Medina, G. (Dirs.). Código Civil y Comercial de la Nación comentado. Tomo II. Ciudad Autónoma de Buenos Aires. La Ley, 136.

13 Ibídem. Conf. Vidal Taquini, C. H. (1999). Régimen de bienes en el matrimonio. Buenos Aires. Astrea, 289, § 257.

14 Conf. Basset, U. C. (2010). La calificación de bienes... Ob. cit., 667-676. 
(respectivamente, bienes propios en copropiedad o condominio y, de ser posible esta terminología jurídica, bienes gananciales en cotitularidad ${ }^{15}$, bienes de condominio ganancial o de ganancialidad conjunta). La diferencia entre estos bienes viene marcada por el momento en que son adquiridos y por el modo en que se realizará su gestión, según particularidades establecidas en el Código, basadas principalmente en la protección de los cónyuges, el interés familiar y la seguridad jurídica de los terceros. En suma, en la comunidad de ganancias pueden coexistir seis masas de bienes.

Serán propios de cada cónyuge aquellos bienes que se hubiesen adquirido con anterioridad a la vigencia del régimen de comunidad de ganancias -sea que esta se produzca a partir de la celebración del matrimonio o con posterioridad, por modificación del régimen de separación de bienes que los cónyuges pactaron primigeniamente mediante convención matrimonial- o durante su vigencia, si tales bienes tienen como causa un acto de liberalidad, pero solo lo serán en la medida de lo taxativamente catalogado en el art. $464 \mathrm{CCCN}$.

En esa lista cerrada de bienes propios aparecen los siguientes: i) bienes aportados por los cónyuges al matrimonio; ii) los adquiridos por herencia, donación o legado (a título gratuito); iii) permuta, basada en el principio de subrogación real; iv) créditos e indemnizaciones que tengan como base una subrogación real; v) los productos de bienes propios; vi) crías de ganado; vii) los bienes adquiridos durante la comunidad por causa o título anterior; viii) los adquiridos por un acto anterior viciado de nulidad relativa pero confirmado durante la comunidad; ix) bienes que retornan al patrimonio del cónyuge por nulidad, resolución, rescisión, revocación de un acto jurídico de causa o título anterior a la comunidad; $x$ ) bienes incorporados por accesión a las cosas propias; xi) las partes indivisas adquiridas por cualquier título por el cónyuge que ya era propietario de una parte indivisa calificada como propia, así como los valores nuevos y otros acrecimientos de los valores mobiliarios propios; xii) la plena propiedad de bienes cuya nuda propiedad se adquirió antes del comienzo de la comunidad, si el usufructo se extingue durante ella, así como la de los bienes gravados con otros derechos reales que se extinguen durante la comunidad; xiii) las ropas y los objetos de uso personal de cada uno de los cónyuges, así como los necesarios para el ejercicio de su trabajo o profesión; xiv) las indemnizaciones por consecuencias no patrimoniales y por daño físico causado a la persona del cónyuge; xv) el derecho a la jubilación o pensión, el derecho a alimentos y, en general, todos los derechos inherentes a la persona; $y$, finalmente, $x v i$ ) la propiedad intelectual, artística o industrial.

15 Conf. Sambrizzi, E. A. (2015). El régimen patrimonial... Ob. cit., 213. 
Respecto de esta enumeración de los bienes propios en el CCCN, Basset considera que "la redacción actual presenta formulaciones más abstractas que el casuismo del Código de Vélez, considerando que 'lo abstracto es más apropiado cuando hay que calificar como propios o gananciales innumerables supuestos concretos cuya variabilidad puede ser infinita"'16. Medina es de la misma opinión, pues entiende que la reforma de 2015 "ha tenido como objetivo hacer una prolija enumeración de los bienes propios aclarando todos aquellos supuestos que hubieran originado confusiones doctrinarias o jurisprudenciales, a un solo artículo (sic), para evitar la búsqueda en distintas normas y la coordinación de distintas fuentes"17.

Los bienes gananciales, por su parte, son aquellos que se adquieren onerosamente durante la vigencia del régimen de comunidad, sea que este hubiese empezado a operar desde la celebración del matrimonio -bien porque los cónyuges lo eligieron mediante convención matrimonial o porque se aplicó supletoriamente a falta de opción expresada por los futuros contrayentes- o desde la modificación del régimen vía convención matrimonial en la forma prevista en el Código -sustituyendo una separación de bienes por una comunidad de ganancias-. Pero los bienes serán gananciales únicamente en la medida de lo enunciado en el art. 465 CCCN y en cuanto resulte aplicable la presunción de ganancialidad prevista en el art. 466 del mismo Código, pues esta también actúa como una fuente de atribución de carácter ganancial a determinados bienes.

Sobre la titularidad de los bienes gananciales, Sambrizzi apunta que:

“[a]l entrar en el análisis de los bienes de carácter ganancial, categoría que sólo existe en el régimen de comunidad, conviene de entrada señalar, para evitar cualquier equívoco, que el hecho de que un bien tenga ese carácter, no puede ser entendido en el sentido de que el mismo sea de propiedad de la comunidad -que al carecer de personalidad jurídica, no puede ser titular de bienes-, o de los dos esposos como condóminos (lo cual no significa, por cierto, que los cónyuges no pueden ser cotitulares de bienes gananciales)"18.

Cada cónyuge será único titular de los bienes gananciales que adquiera durante la vigencia de la comunidad, con un derecho actual sobre los mismos, y, además, con un derecho eventual sobre el cincuenta por ciento del total de los bienes gananciales, incluidos los de titularidad del otro cónyuge,

16 Basset, U. C. et al. (2015). "Tomo III. Artículos 401 a...” Ob. cit., 228.

17 Medina, G. (2015). "Bienes de los cónyuges". En Rivera, J. C. \& Medina, G. (Dirs.). Código Civil y Comercial de la Nación comentado. Tomo II. Ciudad Autónoma de Buenos Aires. La Ley, 142-143.

18 Sambrizzi, E. A. (2015). El régimen patrimonial... Ob. cit., 213. 
que se concreta a la disolución del régimen económico. Este último derecho, primigeniamente eventual, se efectivizará a la disolución del régimen, claro está, siempre que subsista algún bien ganancial en el activo de la comunidad. En tanto no se disuelva ni liquide la comunidad, los bienes gananciales pertenecen al cónyuge que los adquirió, aunque para determinados actos de administración y disposición de algunos de ellos, la vigente normativa civil exija el asentimiento del cónyuge no titular o de una supletoria autorización judicial ${ }^{19}$, como luego veremos.

Estos bienes están enunciados en el art. $465 \mathrm{CCCN}$, pudiendo considerarse a las proposiciones previstas en cada literal como reglas de calificación de los bienes gananciales ${ }^{20}$. Son tales: i) los bienes creados, adquiridos por título oneroso o que empiezan a poseerse durante la comunidad por uno u otro de los cónyuges, o por ambos en conjunto, siempre que no estén incluidos en la lista del art. 464; ii) los adquiridos por hechos fortuitos; iii) los frutos naturales, industriales o civiles de los bienes propios y gananciales; iv) los frutos civiles de la profesión, trabajo, comercio o industria; v) lo devengado como consecuencia del derecho de usufructo de carácter propio; vi) los bienes adquiridos después de la extinción de la comunidad por permuta con otro bien ganancial; vii) los créditos o indemnizaciones que subrogan a otro bien ganancial; viii) los productos de los bienes gananciales, los de las canteras y minas propias, extraídos durante la comunidad; ix) crías de los ganados gananciales; $\mathrm{x}$ ) los bienes adquiridos después de la extinción de la comunidad, si el derecho de incorporarlos al patrimonio fue adquirido por causa o título anterior de carácter oneroso; xi) bienes adquiridos durante la comunidad por un acto anterior viciado de nulidad relativa pero confirmado después de su disolución; xii) los bienes originariamente gananciales que retornan al patrimonio ganancial del cónyuge por nulidad, resolución, rescisión o revocación de un acto jurídico; xiii) los bienes incorporados por accesión a las cosas gananciales; xiv) las partes indivisas adquiridas por el cónyuge que ya era propietario de una parte indivisa de carácter ganancial de un bien al extinguirse la comunidad; y, finalmente, xv) la plena propiedad de bienes cuya nuda propiedad se adquirió a título oneroso durante la comunidad, así como la de aquellos gravados con derechos reales que se extinguen después de aquella.

En una comunidad de ganancias, como se anotó inicialmente, también puede haber bienes propios y bienes gananciales adquiridos por ambos cónyuges. Estos no requieren de una definición concreta pues su naturaleza viene igualmente determinada por el momento en que se adquirieron y está,

19 Conf. Ibídem.

20 Conf. Basset, U. C. et al. (2015). “Tomo III. Artículos 401 a...” Ob. cit., 239. 
además, ajustada a lo regulado en cada caso por los arts. 464 y 465 CCCN, que establecen las reglas para la calificación de los bienes como propios y gananciales, respectivamente. De todos modos, resulta necesario destacar que, según el art. $471 \mathrm{CCCN}$, la administración y disposición de estos bienes corresponde a los cónyuges en conjunto, cualquiera que sea la importancia de la alícuota correspondiente a cada uno. Este último artículo también expresa que a las partes indivisas de estos bienes se aplica lo previsto para la gestión de los bienes propios y de los bienes gananciales. Y dispone que, en todo lo no previsto por él, a las cosas conjuntamente adquiridas se aplicarán las normas del condominio.

El CCCN contiene, además, una regla de presunción legal de ganancialidad de todos los bienes existentes al momento de la extinción de la comunidad. Esta presunción opera cuando no pudiera determinarse la naturaleza propia o ganancial del bien existente en la comunidad a partir del trabajo de subsunción en cualquiera de los casos enumerados en los arts. 464 y 465 CCCN, antes descritos. Se trata de una presunción iuris tantum en tanto admite prueba en contrario. El fundamento último de esta presunción estriba en el hecho de que llegado el momento de la extinción del régimen podría cuestionarse el carácter de determinados bienes, presentándose en especial este inconveniente de determinación respecto de los muebles no registrables. Un problema que puede venir agravado por la facultad legal de los cónyuges de atribuir ganancialidad a determinados bienes propios, que es un acto válido y condice con el principio de libertad contractual que reza el nuevo Código admitiendo la contratación entre cónyuges.

Sobre esta presunción de ganancialidad, Sambrizzi sostiene que:

"si bien la presunción no se encuentra establecida sólo para los bienes con respecto a los cuales puedan caber dudas sobre su carácter de propio o ganancial, sino para todos, lo cierto es que, en la práctica, dicha disposición sólo tiene relevancia para aquellos bienes que, por las circunstancias del caso, sean de difícil calificación en cuanto a su carácter”21.

$\mathrm{Y}$ ante esa dificultad para atribuir la calidad de propios o gananciales a determinados bienes, incluso frente a la aplicación de la mencionada presunción, agrega el citado autor:

"no obstante que la dificultad para determinar la propiedad de los bienes se produce con mayor frecuencia cuando se trata de bienes muebles no registrables, no se encuentran exentos de esa dificultad los bienes inmuebles, ni tam-

21 Sambrizzi, E. A. (2015). El régimen patrimonial... Ob. cit., 246. 
poco los bienes muebles registrables, lo que se advierte si se tiene en cuenta que estas especies de bienes, aún adquiridos durante la vigencia de la comunidad, pueden pertenecer a uno de los esposos como propios, por ejemplo, por haberse producido una subrogación real" 22 .

El art. $466 \mathrm{CCCN}$, además de regular la aplicación de una presunción de ganancialidad sobre los bienes de los cónyuges a la extinción del régimen de comunidad, contiene una serie de reglas orientadas a la prueba del carácter propio o ganancial de estos bienes. La primera y más importante de todas es que los cónyuges pueden demostrar mediante cualquier medio probatorio el carácter ganancial de los bienes. Sin embargo, respecto de la prueba del carácter propio de los bienes la norma contempla una mayor dificultad probatoria, estableciendo textualmente que, frente a terceros, no es suficiente la confesión de los cónyuges. Esta "sería en principio válida entre los cónyuges, pero no respecto de terceros, aunque siempre sujeta al principio de veracidad y orden público de la calificación"23.

Para oponer frente a terceros la prueba del carácter propio de los bienes registrables adquiridos durante la comunidad por inversión o reinversión de bienes propios, el artículo anterior (466 CCCN) requiere que consten en el acto de adquisición las siguientes circunstancias: i) que es una inversión o reinversión de bienes propios; ii) que quede suficientemente determinado el origen de los fondos; y, iii) la conformidad del otro cónyuge, por cuanto de ese modo este declara que el bien pertenece al patrimonio propio del cónyuge adquirente y que no tiene derechos sobre el bien adquirido porque no le es propio ni tampoco es ganancial. La norma en comento agrega que, en caso de que el cónyuge del adquirente no pudiera o no quisiera prestar dicha conformidad, el cónyuge interesado podrá requerir una declaración judicial del carácter propio del bien.

Consecutivamente, tras el tratamiento de las reglas para la calificación de los bienes en la comunidad de ganancias, el Código desarrolla el régimen de deudas de los cónyuges sobre la base del principio de responsabilidad separada o de separación de deudas. Observa Basset, al respecto, que el art. $467 \mathrm{CCCN}$ "integra el régimen de responsabilidad por deudas de los cónyuges en su faz externa: la responsabilidad de los cónyuges frente a terceros" 24 , disponiendo que cada cónyuge responde con todo su patrimonio por las deudas contraídas, sea que el mismo contenga bienes propios o gananciales por él adquiridos. En lo que corresponde a los gastos de conser-

22 Ibídem.

23 Basset, U. C. et al. (2015). “Tomo III. Artículos 401 a...” Ob. cit., 249.

24 Ibídem, 250. 
vación y reparación de las cosas gananciales, el cónyuge que no contrajo la deuda también debe responder frente al acreedor, pero solo con sus bienes gananciales, no con los propios.

Finalmente, de acuerdo con el art. $475 \mathrm{CCCN}$, el régimen de comunidad se extingue por las siguientes causas: i) la muerte comprobada o presunta de uno de los cónyuges; ii) la anulación del matrimonio putativo; iii) el divorcio; iv) la separación judicial de bienes; y, v) la modificación del régimen matrimonial convenido.

\section{Gestión de los bienes en la comunidad de ganancias: contenido y alcance de la exigencia legal del asentimiento conyugal}

El CCCN regula un sistema de titularidad diferenciada en el tratamiento de los bienes que pertenecen a los cónyuges durante la vigencia de la comunidad de ganancias. En este régimen matrimonial existen simultáneamente bienes propios y gananciales de los cónyuges, con independencia de que los adquieran de modo individual o conjunto. La gestión de los bienes constante comunidad de ganancias descansa, en general, sobre el principio de gestión separada ${ }^{25}$. Sin embargo, en forma excepcional, para determinados casos se requiere el asentimiento del otro cónyuge, es decir, de aquel que no es titular de los bienes propios y gananciales a gestionarse. Cabe resaltar que existe una regulación clara y precisa sobre el tipo de actuación requerida al cónyuge no titular, y también de los bienes en relación con los cuales aquella actuación será requerida.

La exigencia de participación del cónyuge no titular para la gestión de ciertos bienes, representa, para algunos autores, una limitación al poder dispositivo del cónyuge titular de los bienes propios y gananciales ${ }^{26}$. Quizá sería mejor ver a dicha exigencia como una garantía que sirve para tutelar el derecho del otro cónyuge sobre los gananciales, respecto de los cuales tiene legítimo derecho desde la vigencia de la comunidad independientemente del tipo de titularidad que recaiga sobre los mismos. Y con efecto inmediato, también como una medida para proteger el interés de la familia. Aunque bien podría terminar siendo traducida como una limitación-garantía, pues

25 Conf. Medina, G. (2015). "Gestión de los bienes en la comunidad". En Rivera, J. C. \& Medina, G. (Dirs.). Código Civil y Comercial de la Nación comentado. Tomo II. Ciudad Autónoma de Buenos Aires. La Ley, 178.

26 Conf. Ibídem; y Sambrizzi, E. A. (2015). El régimen patrimonial... Ob. cit., 333-343. 
esa exigencia será vista desde ambas perspectivas al momento de la realización de los actos de administración y disposición de los bienes conyugales.

En definitiva, las actuaciones propias de la gestión de los bienes en la comunidad de ganancias deben tener como fin último la protección del interés familiar, que es el bien jurídico central que pretende tutelarse, según se desprende de las normas que inspiran el régimen patrimonial del matrimonio en su conjunto. Capparelli aborda el estudio del interés familiar citando las palabras expresadas por Pettigiani en un voto de disidencia ${ }^{27}$ :

"la protección de intereses individuales en la familia debe compatibilizarse con la del interés familiar, que tiene entidad superior y al cual aquellos deben ordenarse, salvo cuando en nombre del propio interés familiar se menoscaben en forma irritante y excesiva los valores que el grupo básico social está llamado a salvaguardar, imposibilitando y frustrando irreparablemente la viabilidad de sus fines"28.

En la doctrina comparada es posible encontrar afirmaciones que sujetan las facultades de disposición y gravamen de los cónyuges al límite implícito del interés familiar (denominado así en aquellos ordenamientos que, a diferencia del argentino ${ }^{29}$, no hacen una referencia expresa a este interés en el apartado correspondiente al régimen patrimonial ${ }^{30}$ ). Este interés de la familia actúa como un principio rector en la gestión de los bienes del matrimonio ${ }^{31}$. Para Ysàs Solanes, el principio en cuestión pone de relieve la existencia de un interés distinto de los intereses particulares o individuales de los cónyuges, y superior, al que estos deben subordinar sus actuaciones, aunque la familia en sí misma no sea considerada un ente susceptible de tener intereses ${ }^{32}$. De ahí que, tanto en el ámbito personal como, especialmen-

27 Se refiere al voto de disidencia expresado en el fallo de la Suprema Corte de la Provincia de Buenos Aires, del 28 de abril de 1988 ("P, M.D. c/ A.E.").

28 Conf. Capparelli, J. C. (2010). La protección del interés familiar en el régimen patrimonial del matrimonio. Buenos Aires. Educa, 38.

29 En el CCCN sí es posible encontrar, en el apartado del régimen patrimonial, menciones expresas al interés familiar (in fine art. 471 y art. 458).

30 En Perú, el principio se desprende implícitamente del precepto constitucional de protección de la familia (art. 4 de la Constitución de 1993) y tiene, además, raigambre civil, pues la finalidad de la regulación de la familia apunta a contribuir a su consolidación y fortalecimiento (art. $233 \mathrm{CC}$ ).

31 Conf. Varsi Rospigliosi, E. (2012). Tratado de Derecho de familia. Derecho familiar patrimonial, relaciones económicas e instituciones supletorias y de amparo familiar. Tomo III. Lima. Gaceta Jurídica, 51; y, Plácido Vilcachagua, A. (2007). "Administración de bienes propios”. En Gutiérrez Camacho, W. (Dir.). Código Civil comentado. Derecho de Familia (Primera parte). Tomo II. $2^{\mathrm{a}}$ ed. Lima. Gaceta Jurídica, 206.

32 Conf. Ysàs Solanes, M. (2005). "Efectos del matrimonio". En Rogel Vide, C. (Coord. 
te, en el patrimonial, se exija a los cónyuges actuar en interés de la familia, exigencia que debe ser interpretada en sentido negativo por cuanto aquellos deben evitar las actuaciones que puedan causar perjuicios a la familia ${ }^{33}$.

La gestión de los bienes en la comunidad de ganancias, cabe recordar, descansa, en general, sobre el principio de gestión separada ${ }^{34}$. Sin embargo, para determinados casos expresamente señalados en las normas pertinentes, se requiere el asentimiento del otro cónyuge, es decir, de aquel que no es titular de los bienes propios y gananciales del cónyuge que quiere administrarlos, enajenarlos o gravarlos. Ello es así porque el alcance de la regla de gestión separada, en casos específicos, necesita ser reconducido hacia los límites del principio del interés familiar.

Respecto de la gestión de los bienes propios, el art. 469 CCCN preceptúa que cada cónyuge tiene la libre administración y disposición, salvo que alguno de dichos bienes tuviera la categoría de vivienda familiar o de muebles indispensables para esta vivienda, pues para los actos dispositivos de los derechos sobre ambos y para la movilización o transporte de los últimos fuera de la referida vivienda, se requiere el asentimiento del cónyuge no titular del bien. Esto último de acuerdo con lo previsto en el art. $456 \mathrm{CCCN}$.

La falta de ese asentimiento, dice la última norma citada, legitima a quien no lo prestó a demandar la nulidad del acto o la restitución de los muebles dentro del plazo de caducidad de seis meses de haberlo conocido, o dentro de seis meses computados desde la extinción del régimen matrimonial. Sobre la sanción prevista, la doctrina se muestra unánime al sostener que el acto celebrado sin asentimiento es anulable y no nulo de pleno derecho ${ }^{35}$. Sambrizzi apoya esta interpretación de la sanción contenida en la norma señalando que:

"la nulidad del acto es de carácter relativo, ya que la misma se dicta en protección del interés del cónyuge cuyo asentimiento fue omitido [...], por lo que el acto podrá ser confirmado"36, pues, acota el autor, "lo cierto es que la omisión de prestar el asentimiento por parte del cónyuge no administrador no afectaba

Gen.). Derecho de familia. Manuales Básicos. Barcelona. Cálamo Producciones Editoriales, 148.

33 Conf. Ibídem.

34 Conf. Basset, U. C. et al. (2015). “Tomo III. Artículos 401 a...” Ob. cit., 253.

35 Conf. Sambrizzi, E. A. (2015). El régimen patrimonial... Ob. cit., 89-100; Basset, U. C. et al. (2015). "Tomo III. Artículos 401 a..." Ob. cit., 254; y Medina, G. (2015). "Disposiciones comunes a todos los regímenes". En Rivera, J. C. \& Medina, G. (Dirs.). Código Civil y Comercial de la Nación comentado. Tomo II. Ciudad Autónoma de Buenos Aires. La Ley, 122.

36 Sambrizzi, E. A. (2015). El régimen patrimonial... Ob. cit., 90. 
ni afecta en absoluto los intereses generales de la comunidad, sino únicamente y en todo caso, un interés particular"37.

El fundamento para requerir el asentimiento conyugal en estos casos, apunta Medina, estriba en que:

"la vivienda habitual, como base física del hogar, así como los muebles de uso ordinario de la familia, son elementos esenciales para la satisfacción de sus necesidades más elementales; y ello con independencia de que su titularidad corresponda a ambos cónyuges, a uno solo de ellos e incluso a un tercero"38.

Por ello, las disposiciones relativas a la vivienda familiar, muy al margen del régimen económico que rija las relaciones patrimoniales de los cónyuges, apuntan a un fin específico:

"tienen por objeto evitar que uno de los cónyuges lleve a cabo unilateralmente actos dispositivos sobre los derechos de la vivienda habitual y, por otra parte, impiden que se disponga unilateralmente de los bienes muebles de uso ordinario de la familia, en cuanto pudiera afectar a la estabilidad de la sede familiar"39.

El supuesto de exigibilidad del asentimiento para los actos de disposición de los derechos sobre la vivienda familiar o para los de disposición y/o transporte de los bienes muebles indispensables de esta vivienda, aparece regulado en el art. 469 CCCN como una excepción frente a la regla de la libre administración y disposición de cada cónyuge sobre sus bienes pro$\operatorname{pios}^{40}$. Pero una vez remitidos al art. $456 \mathrm{CCCN}$, que regula, en estricto, lo atinente a los actos dispositivos de los derechos sobre la vivienda familiar y sus muebles indispensables, se advierte su carácter de norma inderogable y común a todos los regímenes del matrimonio.

Visto así, esa exigencia es aplicable tanto respecto de los bienes propios como de los bienes gananciales de cada cónyuge que se hallen revestidos con las categorías antes enunciadas: i) de vivienda familiar; o, ii) de bienes muebles indispensables de dicha vivienda. La finalidad de la norma es proteger la vivienda de los cónyuges y sus muebles indispensables para la satisfacción de las necesidades más elementales de la familia, con independencia de

37 Ibídem, 94.

38 Medina, G. (2015). “Disposiciones comunes...” Ob. cit., 119-120.

39 Ibídem.

40 Conf. Basset, U. C. et al. (2015). “Tomo III. Artículos 401 a...” Ob. cit., 254. 
la existencia de hijos ${ }^{41} \mathrm{y}$ sin importar el régimen matrimonial que aquellos hubiesen elegido ${ }^{42}$.

El régimen de la vivienda familiar y de sus bienes indispensables forma parte del conjunto de disposiciones comunes a todos los regímenes, al que la doctrina denomina régimen primario imperativo. Sin embargo, el Código no menciona la forma de constitución ni de determinación concreta de la vivienda familiar (en caso que los cónyuges tuvieran varios inmuebles) y de los muebles que indispensablemente la componen. De darse el caso, del total de bienes inmuebles que tuvieran los cónyuges (fueran propios o gananciales), solo uno de aquellos podría constituirse como vivienda familiar. De haber sido la voluntad del legislador que más de uno de sus bienes pudieran tener dicha calidad, en lugar de haber regulado "vivienda familiar" en todo caso hubiera dicho "viviendas familiares". Como emplea la expresión "vivienda familiar" en su acepción singular, debe entenderse su referencia a una sola vivienda y no a varias ${ }^{43}$. Con los muebles, el asunto se torna más complejo, especialmente cuando se trata de muebles no registrables, pues debido a sus características, su titularidad podría presentarse, en muchos casos, incierta e indeterminable y su desplazamiento con menor sujeción a control y persecución.

Como tema aparte, en lo que se refiere a los actos de administración y disposición de los bienes gananciales, el art. 470 CCCN establece también un ámbito de libertad en la gestión a favor del cónyuge que los hubiera adquirido dentro de la vigencia de la comunidad. Sin embargo, fiel a esa tendencia tuitiva del interés familiar y protectora del derecho del cónyuge no titular sobre los gananciales ${ }^{44}$, la misma disposición contiene cinco supuestos en los cuales se requiere el asentimiento del cónyuge no titular de los bienes gananciales para que estos puedan ser enajenados o gravados. Se requiere, por tanto, el asentimiento para enajenar o gravar: i) los bienes registrables; ii) las acciones nominativas no endosables y las no cartulares, con excepción de las autorizadas para la oferta pública; iii) las participaciones en sociedades no exceptuadas en el caso anterior; y iv) los establecimientos comerciales, industriales o agropecuarios. Adicionalmente, dicho asentimiento es exigido para las promesas de los actos comprendidos en los supuestos mencionados.

La norma en comento no indica cuál sería la sanción resultante ante la falta de asentimiento, pero, vía aplicación analógica, la consecuencia más inmediata sería la misma reservada para el caso de disposición de la vivien-

41 Conf. Medina, G. (2015). "Disposiciones comunes..." Ob. cit., 122.

42 Conf. Basset, U. C. et al. (2015). “Tomo III. Artículos 401 a...” Ob. cit., 297-209.

43 Conf. Medina, G. (2015). "Disposiciones comunes..." Ob. cit., 121.

44 Conf. Basset, U. C. et al. (2015). “Tomo III. Artículos 401 a...” Ob. cit., 256-257. 
da familiar sin asentimiento conyugal; lógica que se extiende con relación al plazo para accionar. Me refiero a la nulidad del acto de enajenación o gravamen de los bienes gananciales que no se realicen en el marco de lo exigido por el art. 470 CCCN, nulidad que debería ser interpretada en los mismos términos que cuando se abordó el tema de la vivienda familiar. En esta misma línea, Medina opina que, en general, "la falta de asentimiento conyugal o poder conferido por el cónyuge que debe prestarlo es un acto que adolece de nulidad relativa y es invocable por el cónyuge preterido; no obstante, el acto puede ser confirmado por éste" ${ }^{45}$. Señala, además, que la acción de nulidad puede ejercitarse, sin que sea preciso instar la disolución de la comunidad, dentro del plazo de caducidad de seis meses desde que se tomó conocimiento de la celebración del acto, pero no fuera del término de seis meses desde la extinción del régimen patrimonial ${ }^{46}$.

Como acabamos de ver, frente a la regla general de libre disposición y administración que tiene cada cónyuge sobre sus bienes propios y gananciales durante la comunidad, aparece la excepción de la exigibilidad del asentimiento del cónyuge no titular de tales bienes. El contenido y alcance del asentimiento ha sido tratado por la doctrina. Partiendo de su naturaleza jurídica, Medina señala que el asentimiento es un acto jurídico unilateral, entre vivos, a título gratuito, no formal y especial para cada acto, mediante el cual el cónyuge no titular (e incluso el conviviente) simplemente autoriza o expresa su conformidad con el negocio jurídico del consorte, sin hacerse, por ello, parte de dicho negocio ${ }^{47}$. Esto último explica que quien presta el asentimiento no se obligue por las deudas que origine el acto ni responda por cualesquiera otras obligaciones que pudieran devenir con posterioridad. $\mathrm{El}$ asentimiento es una suerte de presupuesto de validez que condiciona el poder dispositivo del cónyuge titular del bien del que se dispone ${ }^{48}$.

Respecto de la forma en que debe prestarse el asentimiento, la regulación específica de la materia no exige una formalidad ad solemnitatem ${ }^{49}$, por lo que podría ser otorgado bajo cualquier forma siempre que su manifestación sea indubitable ${ }^{50}$, ya sea que se presente de modo anticipado, concomitante o posterior al acto. No obstante, el art. 457 CCCN exige expre-

45 Medina, G. (2015). “Gestión de los bienes...” Ob. cit., 180.

46 Conf. Ibídem.

47 Conf. Medina, G. (2015). "Disposiciones comunes..." Ob. cit., 123-124.

48 Conf. Ibídem, 124; y, Basset, U. C. et al. (2015). “Tomo III. Artículos 401 a...” Ob. cit., 211.

49 Conf. Sambrizzi, E. A. (2015). El régimen patrimonial... Ob. cit., 72-76.

50 Conf. Belluscio, A. C. (2008). Manual de Derecho de Familia. $8^{\mathrm{a}}$ ed. Buenos Aires. Astrea, 112, párr. 373; y Hernández, L. B. (2014). "El asentimiento conyugal en el régimen actual y en la reforma proyectada". En Revista de Derecho de Familia y Persona, № 13, 6-7. [Cita Online: AR/DOC/1434/2014]. 
samente que el asentimiento verse sobre el acto mismo respecto del cual se otorga, con la especificación de todos sus elementos constitutivos (precios, plazo, garantías, entre otros), pues se trata de un asentimiento especial. Se proscribe, de este modo, cualquier tipo de asentimiento general prestado anticipadamente ${ }^{51}$.

De otro lado, en lo que respecta a los actos de enajenación o gravamen de los bienes gananciales de cada cónyuge, el art. 459 CCCN permite a los cónyuges otorgarse poder uno a otro para representarse en el ejercicio de las facultades que el régimen matrimonial les atribuyere ${ }^{52}$, haciendo alusión a que, en cuanto al alcance del poder, este no comporta la potestad del representante para darse a sí mismo el asentimiento en los supuestos del art. 456 CCCN, esto es, relativos a la administración y disposición de los derechos sobre la vivienda familiar y sus bienes indispensables. Llama la atención que la norma precise que el representante no puede darse el asentimiento a sí mismo para los casos establecidos en el art. 456 CCCN, pues al decir que esa restricción únicamente es aplicable en tales casos, estaría dejando abierta la posibilidad para darse a sí mismo el asentimiento en supuestos distintos en los que este también es requerido, como sucede con la enajenación y gravamen de ciertos bienes gananciales de cada cónyuge, según se vio. Desde ya, cabe precisar, que no pueden interpretarse en sentido amplio ni aplicarse analógicamente las normas que establecen restricciones ${ }^{53}$.

La regulación del asentimiento también puede generar una cierta expectación doctrinal por su contraste conceptual con el consentimiento ${ }^{54}$. Frente a esto, la jurisprudencia argentina había establecido ya -con relación al Código de Vélez y que resulta perfectamente aplicable al Código vigente- el siguiente criterio:

"Lo que se pretende del cónyuge no titular no es el consentimiento respecto del acto de disposición que se va a celebrar, sino simplemente el asentimiento. Esto tiene importancia porque el mismo sólo implica una declaración de conformidad con un acto jurídico ajeno, es decir concluido por otro"55.

51 Conf. Roveda, E. G. (2015). “El régimen patrimonial...” Ob. cit., 101.

52 Conf. Basset, U. C. et al. (2015). “Tomo III. Artículos 401 a...” Ob. cit., 214-217.

53 Conf. Santillán Santa Cruz, R. (2011). "Aplicación de la analogía en la clausura de servidumbres: un caso de integración jurídica frente a las lagunas del derecho”. En Diálogo con la Jurisprudencia, $\mathrm{N}^{\circ} 151,90-93$.

54 Conf. Medina, G. (2012). "El régimen patrimonial..." Ob. cit., 16, 17.

55 Fallo de primera instancia, CNCiv., sala A, 3/3/1981, ED, 94-569: C1 ${ }^{\text {a }}$ Civ. y Com. La Plata, sala III, 17/12/1992; C2 a Civ. y Com. La Plata, sala III, 14/11/1989, citado por Medina, G. (2015). "Disposiciones comunes a todos los regímenes". Ob. cit., 124. 
Se advierte, entonces, que, a efectos jurídicos, la diferencia entre uno y otro concepto tiene una importante repercusión, pues el consentimiento presupondrá que quien lo manifiesta es cotitular del bien objeto del acto dispositivo y que las consecuencias del acto a celebrar le afectarán en la misma medida que a su codisponente.

También pueden presentarse casos en los que el cónyuge no disponente no quiera o no pueda prestar dicho asentimiento. Ante tales contingencias, el art. 458 CCCN prevé la autorización judicial supletoria del asentimiento del cónyuge, sea porque este se halle impedido para manifestar su voluntad, se niegue injustificadamente a prestarlo perjudicando así el interés general, o no pudiera prestarlo (por ejemplo, por encontrarse restringida su capacidad de ejercicio) ${ }^{56}$. Esta autorización judicial, como cuando el propio cónyuge otorga el asentimiento, no genera para aquel ninguna obligación personal a su cargo, pero sí le será plenamente oponible el acto otorgado con autorización judicial sin cuyo asentimiento se celebró.

Sobre los bienes adquiridos conjuntamente, fueran gananciales o propios, el art. 471 CCCN regula que su administración y disposición corresponde a ambos cónyuges, con independencia de la parte que correspondiera a cada uno, pudiendo solicitarse, en caso de disenso entre ellos, una autorización judicial supletoria en los términos de lo previsto por el art. 458 CCCN. Se encuentra legitimado para accionar aquel que toma la iniciativa del acto. Se dispone, además, que a las partes indivisas de dichos bienes se aplican las normas correspondientes a la gestión de los bienes propios y de los bienes gananciales, que se analizaron con precedencia. La norma bajo comentario también expresa que, en todo lo no previsto por ella, se aplican las disposiciones normativas del condominio, pudiendo el juez de la causa negar cualquier pedido de división de un condominio cuando advirtiera que con aquella se afecta el interés familiar.

\section{La sociedad de gananciales y la gestión de los bienes en el Derecho peruano}

Interesa ahora el estudio de la sociedad de gananciales en la sistemática del CC, específicamente en lo relativo a la gestión de los bienes bajo dicho régimen. $\mathrm{El}$ art. $301 \mathrm{CC}$ regula los bienes que componen el activo de la sociedad de gananciales, precisando que: "En el régimen de sociedad de gananciales puede haber bienes propios de cada cónyuge y bienes de la

56 Conf. Basset, U. C. et al. (2015). “Tomo III. Artículos 401 a...” Ob. cit., 212-214. 
sociedad" 57 . Durante la vigencia del régimen de sociedad de gananciales coexisten tres masas de bienes, que van a estar conformadas por los bienes propios de cada cónyuge y los bienes sociales.

Son bienes propios de cada cónyuge, enumera el art. 302 CC: i) los que aporte al iniciarse el régimen de sociedad de gananciales; ii) los que adquiera durante la vigencia de dicho régimen a título oneroso, cuando la causa de adquisición ha precedido a aquélla; iii) los que adquiera durante la vigencia del régimen a título gratuito; iv) la indemnización por accidentes o por seguros de vida, de daños personales o de enfermedades, deducidas las primas pagadas con bienes de la sociedad; v) los derechos de autor e inventor; vi) los libros, instrumentos y útiles para el ejercicio de la profesión o trabajo, salvo que sean accesorios de una empresa que no tenga la calidad de bien propio; vii) las acciones y las participaciones de sociedades que se distribuyan gratuitamente entre los socios por revaluación del patrimonio social, cuando esas acciones o participaciones sean bien propio; viii) la renta vitalicia a título gratuito y la convenida a título oneroso cuando la contraprestación constituye bien propio; y, ix) los vestidos y objetos de uso personal, así como los diplomas, condecoraciones, correspondencia y recuerdos de familia.

Respecto de estos bienes, cada cónyuge conserva la libre administración y puede disponer de ellos o gravarlos, de conformidad con el art. 303 CC. Sin embargo, tales facultades deben ser ejercidas en armonía con el interés de la familia ${ }^{58}$, que se constituye en un límite implícito al actuar de los cónyuges ${ }^{59}$ y que, en consecuencia, puede justificar la aplicación de algunas medidas para evitar los abusos del cónyuge titular del bien propio.

Son bienes sociales, por su parte, de acuerdo a lo previsto en el art. 310 CC, todos los no comprendidos en el art. 302 CC, incluso los que cualquiera de los cónyuges adquiera por su trabajo, industria o profesión, así como los frutos y productos de todos los bienes propios y de la sociedad; también lo son las rentas de los derechos de autor e inventor. Tienen además la calidad de bienes sociales los edificios construidos a costa del caudal social en suelo propio de uno de los cónyuges, abonándose a este el valor del suelo al momento del reembolso. Estos bienes tienen la calidad de tal por haber

57 Los arts. 310 y 315 CC utilizan, de modo explícito, el concepto de bienes sociales. Con dichos preceptos, el legislador peruano quiso zanjar cualquier posible confusión en la interpretación de la expresión "bienes de la sociedad". Esta expresión no se está refiriendo a los bienes que integran la sociedad de gananciales.

58 Conf. Plácido Vilcachagua, A. (2016). "La naturaleza de la intervención conyugal para disponer bienes sociales en la gestión patrimonial del régimen de sociedad de gananciales y su inconcurrencia como supuesto de ineficacia estructural del acto de disposición". En Actualidad Civil, $\mathrm{N}^{\mathrm{o}} 19,82$.

59 Conf. Plácido Vilcachagua, A. (2007). "Administración de bienes propios”. Ob. cit., 206. 
sido adquiridos desde la vigencia del régimen de gananciales -sea porque operó con la celebración del matrimonio o porque empezó a regir tras haberse modificado el régimen de separación de patrimonios-. Se reputan de titularidad de ambos cónyuges como miembros de la sociedad conyugal, aun cuando los adquiera uno solo de ellos.

En Derecho peruano no existe una tipología de los bienes comunes en función del cónyuge que los adquirió, que permita hablar de bienes sociales de cada cónyuge y bienes sociales conjuntamente adquiridos, como para justificar el establecimiento de unas reglas relativas a la gestión de los bienes sobre la base de esta diferenciación legal. Existe una sola clase de bienes comunes a los cónyuges: los adquiridos onerosamente durante la vigencia de la sociedad de gananciales (con exclusión de los propios de cada cónyuge). Se exige la intervención de ambos cónyuges para su disposición y gravamen, salvo supuestos expresamente previstos. Esto último se desarrolla más adelante por los problemas que genera.

Lo relativo a la administración del patrimonio común es regulado por el art. $313 \mathrm{CC}$ en los siguientes términos:

“Corresponde a ambos cónyuges la administración del patrimonio social. Sin embargo, cualquiera de ellos puede facultar al otro para que asuma exclusivamente dicha administración respecto de todos o de algunos de los bienes. En este caso, el cónyuge administrador indemnizará al otro por los daños y perjuicios que sufra a consecuencia de actos dolosos o culposos".

Este precepto regula la administración del patrimonio social como una atribución que corresponde a ambos cónyuges. No obstante, deja abierta la posibilidad para que cualquiera de ellos pueda facultar al otro a asumir en forma exclusiva dicha administración, ya sea respecto de todos o de algunos de los bienes que conforman el patrimonio común. En este caso, como aparece en la parte final del precepto, el cónyuge administrador deberá indemnizar al otro por los daños y perjuicios que pudiera sufrir a consecuencia de los actos dolosos o culposos realizados en el marco de esa exclusiva administración.

Las reglas aplicables a la disposición de los bienes sociales se encuentran establecidas en el art. 315 CC. Llama la atención que el legislador peruano decidiera regular la disposición de estos bienes en un precepto diferente al de la administración del patrimonio social (art. 313 CC) cuando en ambos casos -como veremos posteriormente- gobierna el principio general de la actuación conjunta. También es cierto, como inmediatamente se podrá advertir, que el precepto regulador de los actos dispositivos contiene unas reglas más específicas que no han sido previstas para la 
administración, pudiendo ser esta la razón que hubiese justificado una regulación separada.

En concreto, refiriéndose a la disposición y gravamen de los bienes sociales, el art. $315 \mathrm{CC}$ prescribe:

"Para disponer de los bienes sociales o gravarlos, se requiere la intervención del marido y la mujer. Empero, cualquiera de ellos puede ejercer tal facultad, si tiene poder especial del otro.

Lo dispuesto en el párrafo anterior no rige para los actos de adquisición de bienes muebles, los cuales pueden ser efectuados por cualquiera de los cónyuges. Tampoco rige en los casos considerados en las leyes especiales".

El régimen peruano de gananciales tiene como regla general la actuación conjunta de los cónyuges en los actos de disposición de los bienes sociales, previéndose la posibilidad de conferirse entre ellos poder especial para dichos actos. Esta norma no hace una distinción entre actos onerosos y gratuitos, siendo posible entender que la regla indicada se aplicará en igual medida para ambos casos.

Ahora bien, es en el marco de esa exigencia de intervención conjunta en los actos de disposición y gravamen de los bienes sociales, que cabe el otorgamiento de un poder especial por uno de los cónyuges en favor del otro, mediante el cual este quede autorizado a ejercer expresamente dichas facultades. La forma que debe revestir dicho poder viene determinada por una regla del acto jurídico en general. Resultaría aplicable el art. 156 CC, cuyo tenor expresa: "Para disponer de la propiedad del representado o gravar sus bienes, se requiere que el encargo conste en forma indubitable y por escritura pública, bajo sanción de nulidad”.

La actuación conjunta de los cónyuges, como dispone el art. 315 CC, se concreta en la intervención simultánea de ambos cónyuges o en la intervención de uno de ellos con poder especial otorgado por el otro cónyuge, mediante el cual delegue las facultades suficientes observando la forma prescrita para ser debidamente representado en un acto de disposición o gravamen de los bienes sociales. En la actuación conjunta mediante poder ${ }^{60}$, el cónyuge interviniente actuará en nombre propio y, además, como apoderado de su consorte. Solo así se puede materializar la intervención de ambos cónyuges en todo su alcance y efectos, como requiere la norma. La actuación de un cónyuge con poder suficiente y acreditado, otorgado por el otro consorte, constituye una forma de cogestionar el acervo común de los cónyuges ${ }^{61}$.

60 Conf. Rams Albesa, J. J. (1992). La sociedad de gananciales. Madrid. Tecnos, 283.

61 Conf. Lacruz Berdejo, J. L. et al. (2010). Elementos de Derecho Civil... Ob. cit., 216. 
$\mathrm{El}$ art. $315 \mathrm{CC}$ en su párrafo segundo dispone que la regla general de la actuación conjunta -que comprende la actuación de un cónyuge con poder especial del otro como una forma particular de codisposición- no rige para los actos de adquisición de bienes muebles, pues estos pueden ser efectuados por cualquiera de los cónyuges. La regla tampoco se aplica para los casos regulados por leyes especiales ${ }^{62}$. Por lo que, con estas dos disposiciones el artículo en cuestión ha querido legitimar la actuación individual de los cónyuges en los supuestos mencionados, para evitar así que la misma pueda ser posteriormente cuestionada por inobservancia de la regla de la intervención conjunta, que, como queda claro, no rige para ellos.

No obstante, en Derecho peruano cabe hablar de la posibilidad de otro supuesto de disposición de bienes comunes que no ha previsto expresamente la norma. Se trata de la disposición individual de bienes comunes sin poder especial del otro cónyuge en supuestos en que sí se requiere su intervención conjunta.

La actuación de un cónyuge con poder especial conferido por el otro, permite mantener intacta la regla de codisposición de los bienes sociales. Pese a ello, autorizada doctrina considera a los actos de disposición realizados por un solo cónyuge sin poder especial como supuestos de ineficacia en los que cabe la ratificación de dicho poder ${ }^{63}$. Parte de la jurisprudencia se pronuncia en el mismo sentido ${ }^{64}$. Sin embargo, esta posibilidad no está recogida en las normas del régimen peruano de sociedad de gananciales.

Que el art. 315 CC no exprese una sanción para la situación antes descrita agrava el problema. Para buscar una solución se interpreta la naturaleza de la intervención conjunta requerida por el art. 315 CC, planteándose si es un requisito de validez o de eficacia del acto. El escenario se torna más complejo ante la formulación de hipótesis que transitan por la nulidad ${ }^{65}$,

62 Véanse estos casos en Santillán Santa Cruz, R. (2020). "Legitimación de los cónyuges para disponer de los bienes comunes bajo un régimen de sociedad de gananciales. Estudios de Derecho español y peruano". En Actualidad Jurídica Iberoamericana, $\mathrm{N}^{\circ} 12$, 648-649.

63 Conf. Torres Vásquez, A. (2007). "Ineficacia del acto jurídico celebrado por el falsus procurator". En Jus Jurisprudencia, N 9, 11. y Fernández Cruz, G. (2016). "La disposición de bienes conyugales. Reflexiones sobre dos instituciones encontradas: la nulidad y la ineficacia sobre la venta de bienes conyugales". En Actualidad Civil, $\mathrm{N}^{\circ}$ 19, 38.

64 Conf. Sentencias de la Corte Suprema Cas. No 3056-2002-Lima, 6 junio 2003 (VLEX32341913); y Cas. No 907-2008-Arequipa, 24 julio 2008 (VLEX-65121325).

65 Conf. Plácido Vilcachagua, A. (2016). "La naturaleza de la intervención..." Ob. cit., 109-110; y Loayza Revilla, J. S. (2016). "La disposición unilateral de los bienes sociales como un supuesto de nulidad virtual”. En Actualidad Civil, Nº 19, 136. 
la ineficacia ${ }^{66}$ e inoponibilidad ${ }^{67}$, hasta la rescisión por disposición de bien ajeno ${ }^{68}$. Y si, finalmente, la tesis de la ineficacia y de la posibilidad de ratificación llegase a tener acogida, la disposición de un bien social sin el poder antes descrito solo podría quedar configurada como un supuesto de "anómala actuación individual", cuya habilitación y efectos encontrarían arraigo en las más recientes decisiones judiciales ${ }^{69}$.

\section{Notas conclusivas}

En Derecho de familia, la ordenación de las relaciones económicas y patrimoniales de los cónyuges entre sí, y respecto a terceros, es un asunto con gran repercusión, y de notable complejidad, especialmente cuando el régimen económico al que se sujetan los cónyuges es de los llamados de comunidad, cuyo tratamiento en los Derechos argentino y peruano presenta notables similitudes, aunque también diferencias legales reseñables.

El modelo de elección y sustitución que hoy opera en el sistema económico matrimonial de Argentina, está vigente en Perú desde la dación del CC de 1984. Con anterioridad a este Código la situación legal del régimen patrimonial en Perú era la misma que estuvo concebida en Argentina hasta 2015. Y aun cuando hoy ambos ordenamientos comparten el mismo modelo de elección y sustitución del régimen patrimonial, no sucede así en cuanto al sistema de calificación y gestión de los bienes que coexisten constante régimen de comunidad.

La reciente incorporación de este sistema de elección y sustitución en el CCCN supuso para el legislador argentino la oportunidad de establecer normas que se ajusten mejor a la realidad socio-familiar que atraviesa en estos tiempos el país. Entre las novedades de este Código se encuentra la tipología de las masas patrimoniales que van a coexistir durante la comunidad de ganancias. Y si bien la administración y disposición de los bienes matrimoniales está presidida por una regla de gestión separada, existen excepciones relacionadas con aquellos bienes que tengan la calidad de vi-

66 Conf. Fernández Bocanegra, L. D. (2014). "La ineficacia generada por el falso representante y el eterno retorno de los justiciables a los laberintos judiciales". En Actualidad Civil, $\mathrm{N}^{\circ} 1,68-83$.

67 Conf. Morales Hervias, R. (2013). "La falta de legitimidad en los contratos inoponibles". En Actualidad Jurídica, No 230, 13-21; y Torres Vásquez, A. (2015). "Inoponibilidad del acto jurídico". En Actualidad Civil, Nº 9, 86-87.

68 Conf. Ninamancco Córdova, F. (2012). "Disposición de bienes sociales por un solo cónyuge”. En Diálogo con la jurisprudencia, N 168, 92; y Fernández Cruz, G. (2016). “La disposición de..." Ob. cit., 32-33.

69 Conf. Santillán Santa Cruz, R. (2020). “Legitimación de los cónyuges...” Ob. cit., 651. 
vienda familiar y con los muebles que se reputen indispensables para la familia. Existen, además, previsiones concretas para la enajenación y gravamen de los bienes gananciales adquiridos por un solo cónyuge (requisito de asentimiento).

En el régimen peruano de gananciales puede haber bienes propios de cada cónyuge y bienes sociales. No existe en Perú -como sí en Argentinauna distinción de los bienes comunes en función del cónyuge que los adquirió, que permita hablar de bienes sociales de cada cónyuge y bienes sociales adquiridos conjuntamente, como para prever a partir de allí unas reglas de gestión diferenciadas. Existe una sola clase de bienes sociales: los adquiridos onerosamente durante la vigencia de la sociedad de gananciales (excluyendo los propios). Como regla general se exige la intervención de ambos cónyuges en la administración y disposición de tales bienes, salvo que uno de ellos otorgara poder especial al otro para realizar estos actos. La representación especial prescrita para la codisposición de los bienes sociales presenta graves problemas en la práctica jurídica.

En Perú, la gestión de los bienes comunes constante sociedad de gananciales sigue siendo un tema debatido. Fuera de los supuestos de actuación individual que expresamente admite el CC, cualquier disposición de bienes sociales por un solo cónyuge encajaría en lo que he venido a denominar una "anómala actuación individual", cuyos efectos suelen ser encausados por la doctrina académica y jurisprudencial hacia un supuesto de ineficacia, respecto del que cabría la ratificación del cónyuge que no intervino en la realización del acto de disposición. En esta materia, el CCCN contiene una clara tipología de los bienes de la comunidad y de las reglas que han de aplicarse para su gestión. Un sistema que difícilmente podría adoptar el CC porque se contrapone con su estructura sistemática y sus reglas, aún restrictivas de la autonomía patrimonial de los cónyuges.

\section{Bibliografía}

Aguilar Llanos, B. (2008). La Familia en el Código Civil peruano. Lima. Ediciones Legales.

Basset, U. C. (2010). La calificación de bienes en la sociedad conyugal: principios, reglas, criterios y supuestos. Buenos Aires. AbeledoPerrot.

Basset, U. C. et al. (2015). "Tomo III. Artículos 401 a 723. Relaciones de Familia”. En Alterini, J. H. (Dir. Gen.). Código Civil y Comercial comentado. Tratado Exegético. Ciudad Autónoma de Buenos Aires. La Ley, 185-263.

Belluscio, A. C. (2008). Manual de Derecho de Familia. $8^{\mathrm{a}}$ ed. Buenos Aires. Astrea.

Cagnasso, A. (2016). "El régimen patrimonial del matrimonio en el nuevo Código Civil y Comercial de la Nación". En El Derecho, Nº 71/-8. 
Capparelli, J. C. (2010). La protección del interés familiar en el régimen patrimonial del matrimonio. Buenos Aires. Educa.

Fernández Bocanegra, L. D. (2014). "La ineficacia generada por el falso representante y el eterno retorno de los justiciables a los laberintos judiciales”. En Actualidad Civil, $\mathrm{N}^{\circ} 1,68-83$.

Fernández Cruz, G. (2016). "La disposición de bienes conyugales. Reflexiones sobre dos instituciones encontradas: la nulidad y la ineficacia sobre la venta de bienes conyugales". En Actualidad Civil, No 19, 24-39.

Hernández, L. B. (2014). "El asentimiento conyugal en el régimen actual y en la reforma proyectada". En Revista de Derecho de Familia y Persona, No 13 . [Cita Online: AR/DOC/1434/2014].

Lacruz Berdejo, J. L. et al. (2010). Elementos de Derecho Civil IV: Familia. $4^{\mathrm{a}}$ ed. Madrid. Dykinson.

Loayza Revilla, J. S. (2016). "La disposición unilateral de los bienes sociales como un supuesto de nulidad virtual”. En Actualidad Civil, No 19, 124-138.

Martínez de Aguirre Aldaz, C. (2016). "La economía del matrimonio. Capitulaciones matrimoniales”. En Martínez de Aguirre Aldaz, C. (Coord.). Curso de Derecho Civil. Derecho de Familia. Vol. IV. $5^{\text {a }}$ ed. Madrid. Edisofer, 223-248.

Medina, G. (2012). "El régimen patrimonial del matrimonio en la reforma al Código Civil y Comercial”. En Revista de Derecho de Familia y Persona, No 3 . [Cita Online: AR/DOC/5230/2012].

Medina, G. (2015). "Bienes de los cónyuges". En Rivera, J. C. \& Medina, G. (Dirs.). Código Civil y Comercial de la Nación comentado. Tomo II. Ciudad Autónoma de Buenos Aires. La Ley, 139-169.

Medina, G. (2015). "Disposiciones comunes a todos los regímenes”. En Rivera, J. C. \& Medina, G. (Dirs.). Código Civil y Comercial de la Nación comentado. Tomo II. Ciudad Autónoma de Buenos Aires. La Ley, 113-134.

Medina, G. (2015). "Disposiciones generales del Régimen de comunidad”. En Rivera, J. C. \& Medina, G. (Dirs.). Código Civil y Comercial de la Nación comentado. Tomo II. Ciudad Autónoma de Buenos Aires. La Ley, 135-138.

Medina, G. (2015). "Gestión de los bienes en la comunidad”. En Rivera, J. C. \& Medina, G. (Dirs.). Código Civil y Comercial de la Nación comentado. Tomo II. Ciudad Autónoma de Buenos Aires. La Ley, 177-187.

Morales Hervias, R. (2013). "La falta de legitimidad en los contratos inoponibles". En Actualidad Jurídica, $\mathrm{N}^{\mathrm{o}} 230,13-21$.

Ninamancco Córdova, F. (2012). "Disposición de bienes sociales por un solo cónyuge". En Diálogo con la jurisprudencia, $\mathrm{N}^{\circ} 168,92$.

Plácido Vilcachagua, A. (2007). "Administración de bienes propios”. En Gutiérrez Camacho, W. (Dir.). Código Civil comentado. Derecho de Familia (Primera parte). Tomo II. $2^{\mathrm{a}}$ ed. Lima. Gaceta Jurídica, 205-207.

Plácido Vilcachagua, A. (2007). "Elección y formalidades del régimen patrimonial”. En Gutiérrez Camacho, W. (Dir.). Código Civil comentado. Derecho de Familia (Primera parte). Tomo II. $2^{\mathrm{a}}$ ed. Lima. Gaceta Jurídica, 175-182.

Plácido Vilcachagua, A. (2007). "Sustitución voluntaria del régimen patrimonial". En Gutiérrez Camacho, W. (Dir.). Código Civil comentado. Derecho de Familia (Primera parte). Tomo II. $2^{\mathrm{a}}$ ed. Lima. Gaceta Jurídica, 183-185. 
Plácido Vilcachagua, A. (2016). "La naturaleza de la intervención conyugal para disponer bienes sociales en la gestión patrimonial del régimen de sociedad de gananciales y su inconcurrencia como supuesto de ineficacia estructural del acto de disposición”. En Actualidad Civil, No 19, 40-110.

Rams Albesa, J. J. (1992). La sociedad de gananciales. Madrid. Tecnos.

Roveda, E. G. (2015). “Convenciones matrimoniales”. En Rivera, J. C. \& Medina, G. (Dirs.). Código Civil y Comercial de la Nación comentado. Tomo II. Ciudad Autónoma de Buenos Aires. La Ley, 97-108.

Sambrizzi, E. A. (2015). El régimen patrimonial del matrimonio en el nuevo Código Civil y Comercial. Ciudad Autónoma de Buenos Aires. Thomson Reuters La Ley.

Santillán Santa Cruz, R. (2011). “Aplicación de la analogía en la clausura de servidumbres: un caso de integración jurídica frente a las lagunas del derecho”. En Diálogo con la Jurisprudencia, No 151, 85-101.

Santillán Santa Cruz, R. (2020). "Legitimación de los cónyuges para disponer de los bienes comunes bajo un régimen de sociedad de gananciales. Estudios de Derecho español y peruano”. En Actualidad Jurídica Iberoamericana, No 12, 620-657.

Torres Vásquez, A. (2007). "Ineficacia del acto jurídico celebrado por el falsus procurator”. En Jus Jurisprudencia, Nº 9, 7-12.

Torres Vásquez, A. (2015). "Inoponibilidad del acto jurídico". En Actualidad Civil, N 9, 78-87.

Varsi Rospigliosi, E. (2012). Tratado de Derecho de familia. Derecho familiar patrimonial, relaciones económicas e instituciones supletorias y de amparo familiar. Tomo III. Lima. Gaceta Jurídica.

Vidal Taquini, C. H. (1999). Régimen de bienes en el matrimonio. Buenos Aires. Astrea.

Ysàs Solanes, M. (2005). "Efectos del matrimonio". En Rogel Vide, C. (Coord. Gen.). Derecho de familia. Manuales Básicos. Barcelona. Cálamo Producciones Editoriales, 143-151. 